\title{
Changes in Concentrations of Residual Chlorine and Trihalomethanes with Activated Carbon under Various Heating Conditions
}

\author{
Takayuki URATA ${ }^{1,2)}$, Shuzo TOKUMITSU'), Ryotaro KIYONO ${ }^{1)}$ and Masayasu TASAKA ${ }^{12}$ \\ 1) Graduate School of Science and Technology, Shinshu University \\ (4-17-1 Wakasato, Nagano 380-8553) \\ ${ }^{21}$ Home Appliance and Housing Electronics Research Laboratory, Home Appliance \\ and Housing Electronics Company, Matsushita Electric Industrial Co., Ltd. \\ (2-2-8 Hinode-cho, Toyonaka, Osaka 561-0821)
}

[Received March 31, 2000]

\begin{abstract}
Summary
To establish a method for removing residual chlorine and trihalomethanes from hot water effectively, an activated carbon column was placed in an electric pot. The variation in concentrations of those compounds was measured by altering the setting position of the activated carbon column and the flow rate of the test solution in the column.

Activated carbon was found to act as a catalyst of the decomposition of residual chlorine. Removal capability based on decomposition decreased with increase in space velocity, and increased with temperature rise. Although activated carbon serves as adsorbent for the removal of trihalomethanes, the amount of trihalomethanes absorbed in activated carbon was quite small in hot water.

The efficiency of residual chlorine removal was low when the activated carbon column was placed at the bottom of the pot. To realize a greater efficiency of the removal, a higher flow rate of test solution through the activated carbon column was required. When the column was placed at the outlet of solution circulation pipe, considerable part of residual chlorine was removed. As a consequence of removing residual chlorine the generation of trihalomethanes was prevented. The concentration of trihalomethanes in solution decreased when the solution was kept hot. The lifespan of activated carbon is very long since it acts as catalyst but not as adsorbent.
\end{abstract}

Key words: residual chlorine, trihalomethanes, activated carbon, circulation

\section{INTRODUCTION}

Some materials which cause so-called bleaching powder odor such as trichloroamine ${ }^{1}$, etc. and/or residual chlorine which generates such materials are present in tap water. Moreover, by-product compounds of chlorination such as trihalomethanes have also been dis- covered $^{2)}$, and their toxicity has been pointed out ${ }^{3)}$. Various researches and studies have so far been performed on the subject ${ }^{461}$. In Japan, in the Tap Water Quality Standard (Ordinance of the Ministry of Health and Welfare) of 1992, trihalomethanes were specified as items relating to health while other by-products of disinfection such as haloacetic acid were set as items to be 
monitored $^{7}$.

Tap water is consumed with or without heat treatment. Residual chlorine decreases and halide by-products in water may increase or decrease by heat treatment ${ }^{8-16}$. It is reported that the nonvolatile final form of the by-product is haloacetic acid and the volatile final form is trihalomethanes ${ }^{17}$. According to Takahashi et al., trihalomethanes disappeared after 3 to 6 hours of heating in the electric pot, but disappeared after 5 to 10 minutes of continuous boiling in the ket$t^{1 e^{17}}$. The change in concentrations of residual chlorine, trihalomethanes and 2-methylisoborneol content in tap water by heating was examined in our previous paper $^{18}$. Even if trihalomethanes decrease by heating, residual chlorine in the water may again produce trihalomethanes. It took no less than 2.5 hours for trihalomethanes to disappear. It is interesting to find a more effective method to remove trihalomethanes.

To remove trihalomethanes effectively, removal of residual chlorine is very important. There is almost no method of removing residual chlorine existing in hot water without boiling the solution. The purpose of the present study is to establish an effective method for removing residual chlorine and trihalomethanes.

\section{EXPERIMENTAL}

\section{Test solutions}

Tap water supplied from waterworks of Toyonaka City, Osaka Prefecture was used. High-purity water was obtained by ultrapure water system (RFG 40 type Low TOC system) of Millipore Co. Ltd. High-purity water resistivity was found to exceed $18 \mathrm{M} \Omega \cdot \mathrm{cm}$.

Test solutions for residual chlorine were prepared by adding sodium hypochlorite to tap or high-purity water and the concentration of residual chlorine was $1 \pm$ $0.05 \mathrm{mg} / \ell$. Test solutions for trihalomethanes were made by adding $\mathrm{CHCl}_{3}, \mathrm{CHBrCl}_{2}, \mathrm{CHBr}_{2} \mathrm{Cl}$ and $\mathrm{CHBr}_{3}$ to tap or high-purity water. Their concentrations were $20,10,5$ and $3 \mathrm{mg} / \ell$, respectively. The total concentration of trihalomethanes was about $40 \mu \mathrm{g} / \ell$. Over $5 \%$ chlorine was used for sodium hypochlorite. $0.1 \% o$ tolidine was used to prepare residual chlorine solution. Sodium hypochlorite solution was of practical grade, trihalomethanes were of grade suitable for trihalomethane analysis and other reagents were of special grade from Wako Co. Ltd.

\section{Experimental equipment}

An electric thermo-pot was used with modification as shown in Fig. 1. A switching valve was installed to circulate water inside the pot. Applied voltage for the pump could be freely changed. The water volume in the pot is $3 \ell$ and the electric power of the heater is $1000 \mathrm{~W}$.

A polypropylene column with inside diameter $\phi 40 \mathrm{~mm}$ was filled with activated carbon. The top and the bottom of the column were covered with nonwoven fabric or mesh of $0.8 \mathrm{~mm}$ aperture to prevent outflow.

\section{Analysis}

\section{Residual chlorine}

Residual chlorine was quantitatively determined by absorptiometry of $o$-tolidine using a Shimadzu spectrophotometer UV-240"11.

\section{Trihalomethanes}

Trihalomethanes were measured by the head-space and solvent extraction-method of the Shimadzu gas chromatograph GC-15A with ECD (electron capture detector). The glass column having inside diameter $\phi 3$ $\mathrm{mm}$ and length $3 \mathrm{~m}$ was filled with $20 \%$ silicone DC550/Chomosorb W (60 - 80 mesh). Oven temperature was maintained at $90{ }^{\circ} \mathrm{C}$, injection temperature at $170{ }^{\circ} \mathrm{C}$ and detector temperature at $250{ }^{\circ} \mathrm{C}$. An ECD (63Ni) detector was used. $\mathrm{N}_{2}$ carrier gas purity was $99.999 \%$. Sample injection volume was $3 \mu \ell$. Analy-

(c)

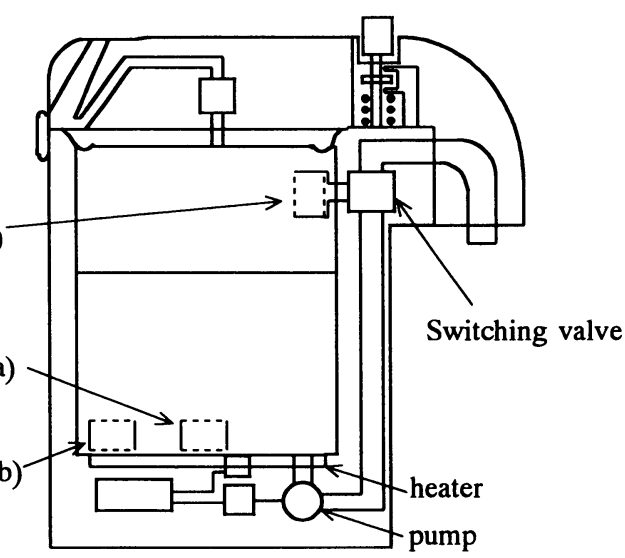

Fig. 1 Schematic diagram of electric pot with the activated carbon colum (a) at the center, (b) at the edge of bottom, and (c) at the outlet of circulation pipe 
sis was carried out in accordance with the Japan Water Works Association Regulations.

\section{Activated carbon}

SXJ activated carbon of Kuraray Chemical Co. Ltd. was used. The activated carbon was prepared with coal and spherical in shape.

Some components dissolved from SXJ activated carbon in hot water were measured by the Hitachi Atomic Adsorption Spectrophoto meter Z-6100. When $10 \mathrm{~g}$ SXJ activated carbon was added to $1 \ell$ high purity water and boiled for 1 hour, the concentrations of some alkali metals and others were very low as shown in Table 1.

The change in component concentrations was measured by altering the setting position of SXJ activated carbon column. The filling density of SXJ activated carbon column was $0.5 \mathrm{~g} / \mathrm{m} \ell$.

\section{RESULTS AND DISCUSSION}

Residual chlorine and trihalomethanes removal by activated carbon under various temperatures

(1) Residual chlorine removal by activated carbon

Test solution was prepared by adding sodium hypochlorite to high-purity water. The concentration of residual chlorine was $1 \pm 0.05 \mathrm{mg} / \ell$. The column was filled with $10 \mathrm{~g}$ SXJ activated carbon. The percentages of residual chlorine by eq. (1) against temperature for various space velocity (SV) are shown in Fig. 2.
Percentage of residual chlorine $(\%)=\left(c^{\mathrm{p}} / c^{f}\right) \times 100$

where $c^{p}$ and $c^{\mathrm{f}}$ are the concentrations of residual chlorine in permeated test solution and in feed test solution $(\mathrm{mg} / \ell)$, respectively. SV was determined by eq. (2)

$$
\mathrm{SV}\left(\mathrm{h}^{-1}\right)=V^{f} / V^{a c}
$$

where $V^{f}(\ell / \mathrm{h})$ and $V^{a c}(\ell)$ are the volume of feed test solution flows into the column for 1 hour and the volume of activated carbon, respectively. As shown in Fig. 2 , the removed percentage of residual chlorine by activated carbon was greater for smaller SV and higher water temperature.

It should be noted that activated carbon acts as catalyst in the following reaction for residual chlorine removal $^{19}$ :

$$
2 \mathrm{Cl}_{2}+2 \mathrm{H}_{2} \mathrm{O} \rightarrow 4 \mathrm{HCl}+\mathrm{O}_{2}
$$

The reaction of eq. (3) proceeded more rapidly in the presence of activated carbon, at smaller SV and higher temperature as seen from Fig. 2.

(2) Trihalomethanes removal by activated carbon

Activated carbon acts as adsorbent for the removal of trihalomethanes ${ }^{12}$. The amount of trihalomethanes absorbed in activated carbon appeared to change with temperature. Chloroform is a main constituent of trihalomethanes. Chloroform absorption at equilibrium was measured and the results are shown in Fig. 3. The

Table 1 Concentration of some elements dissolved from SXJ activated carbon

\begin{tabular}{lrrrrrr}
\hline Elution component & $\mathrm{K}$ & $\mathrm{Na}$ & $\mathrm{Ca}$ & $\mathrm{Mg}$ & $\mathrm{Mn}$ & $\mathrm{Fe}$ \\
Concentration $(\mathrm{mg} / \ell)$ & 0.07 & 0.18 & 1.05 & $<0.01$ & $<0.01$ & $<0.01$ \\
\hline
\end{tabular}

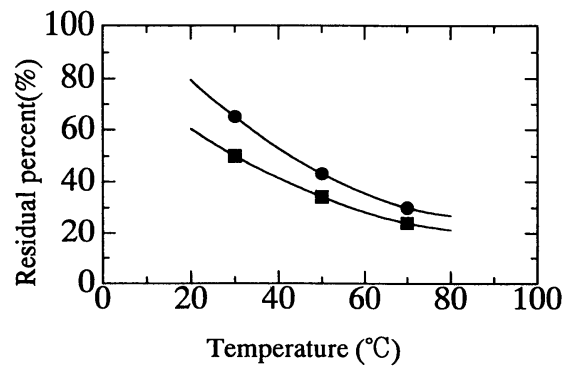

Fig. 2 Residual chlorine percentages as function of temperature Test solutions were passed through the activated carbon column with SV: 
amount absorbed at $90{ }^{\circ} \mathrm{C}$ was less than $1 / 10$ compared with that at $30{ }^{\circ} \mathrm{C}$. When the concentration of chloroform was $100 \mu \mathrm{g} / \ell, 1 \mathrm{~g}$ activated carbon could deal with only $1 \ell$ or less of water at $90^{\circ} \mathrm{C}$, while it could deal with $30 \ell$ at $30{ }^{\circ} \mathrm{C}$.

\section{Changes in residual chlorine and trihalomethanes concentrations by activated carbon column placed on pot bottom}

Changes in residual chlorine and trihalomethanes concentrations by activated carbon column on pot bottom using test solution prepared with highpurity water

The changes of residual percentages of residual chlorine and trihalomethane in test solution prepared with high-purity water against heating time are shown in Fig. 4. The activated carbon column was placed on pot bottom as shown in Fig. 1. The relationship between residual chlorine percentage and the amount of activated carbon is shown in Fig. 5. The activated carbon column was placed at either the center or the edge of the pot bottom.

(1) Residual chlorine

After boiling of the solution, residual chlorine decreased with increase in the amounts of activated carbon and the length of heating time. The solution was passed through the activated carbon column by convection, and residual chlorine was decomposed by the activated carbon acting as a catalyst. Solution temperature increased with heating time. The removal of residual chlorine was thus larger for greater the amount of activated carbon and the length of heating time. The decomposition of residual chlorine was dependent on the site of the activated carbon column. If the activated carbon column is placed at the center of the pot bottom, the convectional flow through the column increases. As-

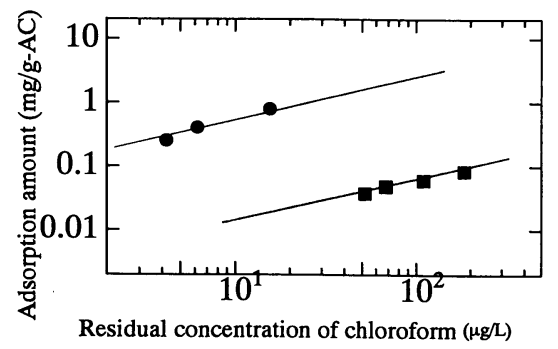

Fig. 3 Adsorption isotherm of chloroform Temperature: $\mathbf{0}, 30{ }^{\circ} \mathrm{C} ; \mathbf{\square}, 90{ }^{\circ} \mathrm{C}$ suming the concentration of residual chlorine $c(\mathrm{mg} / \ell)$ to be the same throughout the system at time $t$ (min), it may be expressed as,

$$
c=c_{0} \exp (-K J t / V)
$$

where $V(\ell)$ is the volume of solution in pot, $c_{0}$. the initial concentration of residual chlorine, $J(\ell / \mathrm{min})$ the flow rate, and $K$ is the removal of residual chlorine. $K$ is defined by $\left(c_{1}-c_{2}\right) / c_{1}$ where $c_{1}$ is the concentration of residual chlorine at the column inlet and $c_{2}$ that at the outlet. Theoretical curves calculated with eq (4) are shown in Fig. 6. Test solution temperature increased with heating time and the removal of residual chlorine by activated carbon became greater. $K$ should increase with time, but in this study it was treated essentially as constant. At SV of $1800 \mathrm{~h}^{-1}$ or less and test solution temperature of $20{ }^{\circ} \mathrm{C}, K$ was over 0.4 as evident from Fig. 2. As shown in Fig. 6, residual chlorine is seen to remain over $0.2(20 \%)$ at boiling point $(t=18)$ when $J$ was $0.2 \mathrm{l} / \mathrm{min}$ and even when $K$ is
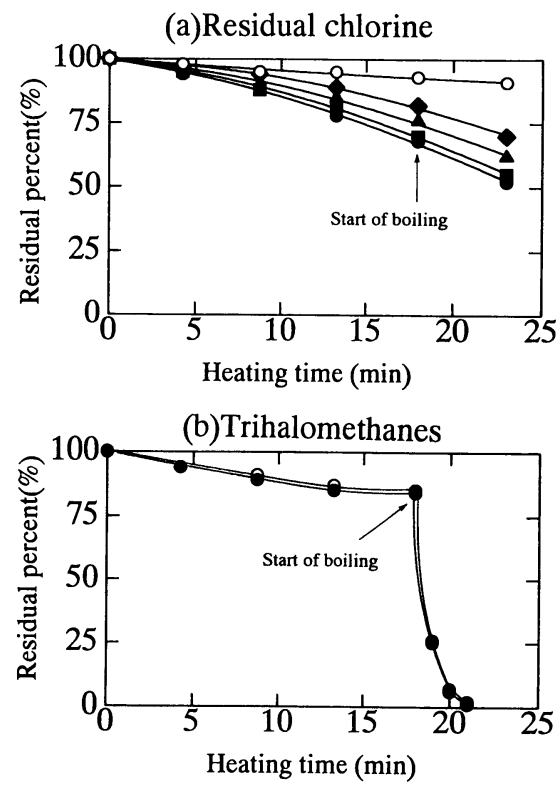

Fig. 4 Residual percentages of (a) residual chlorine and (b) trihalomethanes against heating time. Test solution was prepared with high-purity water.

Activated carbon column was placed at the edge of bottom.

Amount of activated carbon $(\mathrm{g}): \bigcirc, 0$; $10 ;$

$14 ; \mathbf{\square}, 20 ; \bullet, 23$ 
$1.0(100 \%) . J$ should be high to achieve the low residual percentage of residual chlorine.

(2) Trihalomethanes

Activated carbon was not directly effective for removing trihalomethanes, since the amount of trihalomethanes absorbed in activated carbon was small in hot water. If all components of trihalomethanes are adsorbed according to the adsorption isotherm in Fig. 3, $20 \mathrm{~g}$ of activated carbon may be used to treat $15 \ell$ of solution at $90{ }^{\circ} \mathrm{C}$, containing $40 \mu \mathrm{g} / \ell$ trihalomethanes. In hot solution, trihalomethanes was slightly removed by adsorption in activated carbon.

Changes in residual chlorine and trihalomethanes concentrations by activated carbon column on pot bottom using test solution prepared with tap water

The change in residual percentages of residual chlorine and trihalomethane in test solution prepared

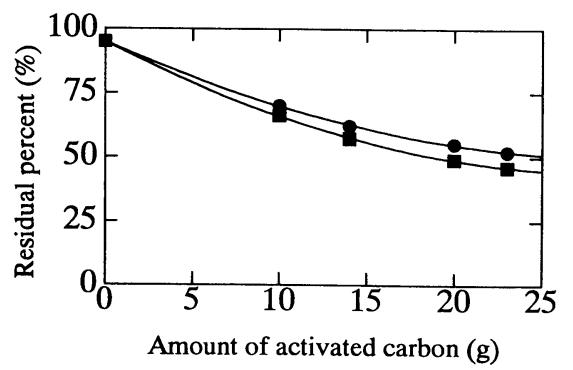

Fig. 5 Residual percentages of residual chlorine at $5 \mathrm{~min}$ after boiling with different amount of activated carbon.

Test solution was prepared with high-purity water.

Activated carbon column was placed at the edge of bottom (1) and the center of bottom

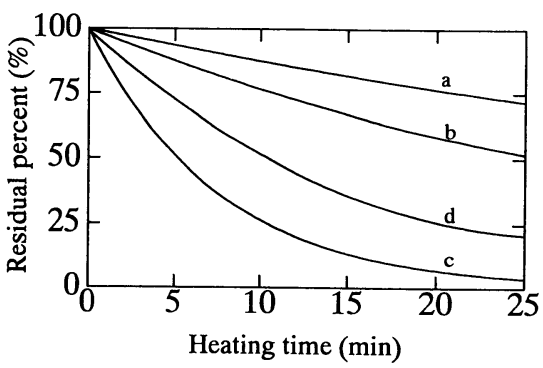

Fig. 6 Theoretical curve calculated with eq. (4). The value of the removal ratio $(\%)$ and the flow rate ( $\ell / \mathrm{min}.):$ a, $(40 \%, 0.1 \mathrm{\ell} / \mathrm{min}$.$) ; b, (40 \%, 0.2$

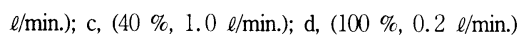

with tap water against heating time is shown in Fig. 7. Activated carbon column was placed on the edge of the pot bottom, as shown in Fig. 1.

(1) Residual chlorine

Residual chlorine in the test solution prepared with tap water was less compared to the solution prepared with high-purity water. The concentration of residual chlorine in test solution using activated carbon column was slightly lower compared to that using no column. Residual chlorine was removed by reactions with organic substance in tap water on activated carbon. Flow rate $(J)$ had to be larger to decrease residual chlorine, in the case of tap water.

(2) Trihalomethanes

Trihalomethanes in the test solution prepared with tap water increased with heating time. Activated carbon did not effectively remove trihalomethanes in the test solution prepared with high-purity water, but decreased trihalomethanes in solution prepared with tap water. Activated carbon could not adsorb trihalomethanes in hot water, but reduced residual chlorine. Activated carbon thus prevents trihalomethane genera-
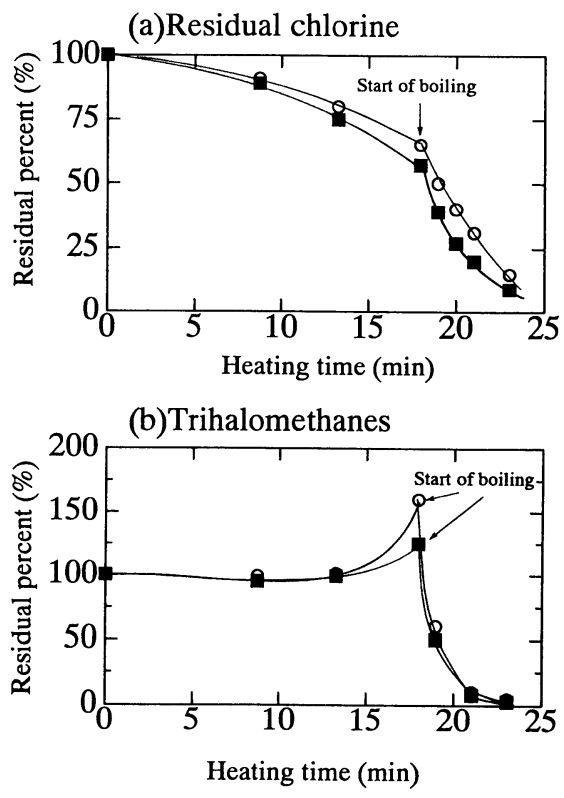

Fig. 7 Residual percentages of (a) residual chlorine and (b) trihalomethanes with heating time. Test solution was prepared with tap water. Activated carbon column was placed at edge of bottom.

Amount of activated carbon (g): $\bigcirc, 0$;

20 
tion due to reactions of residual chlorine with organic compounds. The residual chlorine must be removed in order to prevent trihalomethane generation.

\section{Change in concentrations of residual chlorine and trihalomethanes by activated carbon column at outlet of circulation pipe}

Change in concentrations of residual chlorine and trihalomethanes by activated carbon at outlet of circulation pipe using test solution prepared with high-purity water

The change in residual percentages of residual chlorine and trihalomethane in test solution prepared with high-purity water against heating time is shown in Fig. 8. Activated carbon was placed at the outlet of the circulation pipe as shown in Fig. 1.

(1) Residual chlorine

The variation in residual chlorine content in test solution against heating time was independent of flow rate of water when activated carbon column was not used. This is because residual chlorine is nonvolatile $^{\text {(1) }}$.

When water was passed through the activated carbon column at the outlet of circulating pipe, residual chlorine rapidly decreased with increase in the amount of activated carbon in the column. The removal of residual chlorine $K$ in eq. (4) increased with the amount of activated carbon. The variation in residual chlorine content was independent of circulating flow rate $J$. When the circulating flow rate of test solution $J$ was high, SV became high and the removal of residual chlorine $K$ became low. When $K$ was dependent on SV as in this study, the concentration of residual chlorine $c$ was essentially independent of test solution flow rate.

(2) Trihalomethanes

In the experiments before boiling, the residual percentage of trihalomethanes decreased with heating time. The residual percentages under circulating the test solution were slightly lower than those under not circulating as shown in Fig. 8b. On the other hand, a greater removal of trihalomethanes by vaporization was observed. This is because the contact area between the vapor phase and the liquid phase becomes larger when test solution was boiled and circulated.

Change in concentrations of residual chlorine and trihalomethanes by activated carbon column at outlet of circulation pipe using test solution prepared with tap water

The change in residual percentages of residual chlorine and trihalomethane in test solution prepared with tap water against heating time is shown in Fig. 9. Activated carbon column was placed at the outlet of circulation pipe as shown in Fig. 1.

(1) Residual chlorine

Residual chlorine considerably decreased by placing an activated carbon column at the outlet of the circulation pipe. The residual percentage of residual chlorine was $10 \%$ or less at the start of boiling. It was possible to remove residual chlorine by the small amount of activated carbon in hot water.

(2) Trihalomethanes

Trihalomethanes in test solution prepared with tap water increased with heating time when no activated carbon column was used before boiling. This is because trihalomethanes were generated by reaction of residual chlorine with precursor or intermediate organic

(a)Residual chlorine

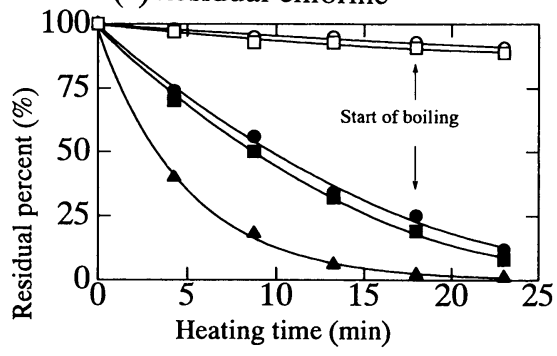

(b) Trihalomethanes start of boiling

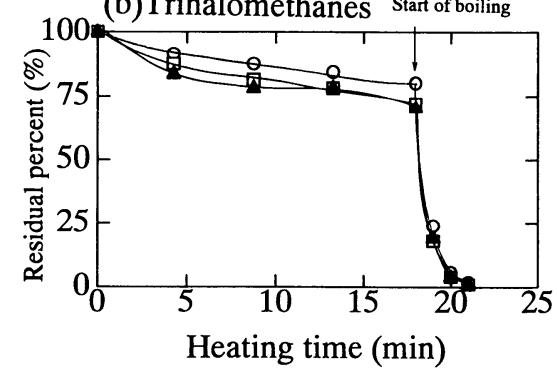

Fig. 8 Residual percentages of (a) residual chlorine and (b) trihalomethanes with heating time. Test solution was prepared with high-purity water.

Activated carbon column was placed at the outlet of circulation pipe.

\footnotetext{
Amounts of activated carbon $(\mathrm{g})$ and flow rate ( $/ / \mathrm{min}.): \bigcirc,(0 \mathrm{~g}, 0.0 \mathrm{l} / \mathrm{min}.) ; \square,(0 \mathrm{~g}, 2.5 \mathrm{l} / \mathrm{min}$.);

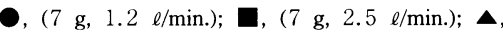
(25 g, $2.5 \mathrm{l} / \mathrm{min}$.)
} 
substances in tap water. On the other hand, the concentration of trihalomethanes never exceeded the initial concentration during heating when the activated carbon column was used. This is because trihalomethanes generated during heating decreased due to the reduction in residual chlorine by activated carbon. A rapid decrease in trihalomethanes was observed after boiling of the solution. The absolute value of the increase of trihalomethanes due to the generation from residual chlorine was less than that of the decrease of trihalomethanes due to the vaporization.

The test solutions were kept hot at $95{ }^{\circ} \mathrm{C}$ after 5 min boiling. The change in the concentration of trihalomethanes against time is shown in Fig. 10. Trihalomethanes increased when the activated carbon column was not used. But, trihalomethanes decreased constantly during heating and circulating the solution through the activated carbon column. The circulation of the solution in the activated carbon column during heating was found quite effective for removing not only re-
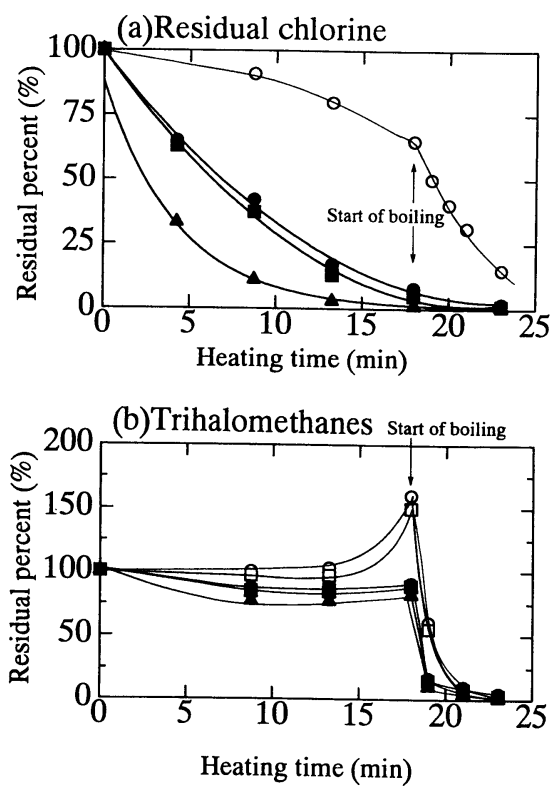

Fig. 9 Residual percentages of (a) residual chlorine and (b) trihalomethanes with heating time. Test solution was prepared with tap water. Activated carbon column was placed at the outlet of circulation pipe.

Amounts of activated carbon $(\mathrm{g})$ and flow rate

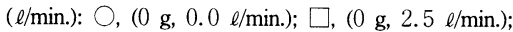
, (7 g, 1.2 l/min.); $\mathbf{\square},(7 \mathrm{~g}, 2.5 \mathrm{l} / \mathrm{min}.) ; \boldsymbol{\Delta}$,

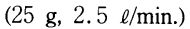

sidual chlorine but also trihalomethanes. The lifespan of activated carbon is very long since it acts as catalyst but not as adsorbent.

\section{Volatilized trihalomethanes}

Trihalomethanes volatilized in a room by boiling the water may be inhaled in the human body. Various research and studies have so far been carried out about contamination of air in residences by volatile organochlorine compounds including chloroform ${ }^{202 \text { 2). In }}$ the case where $3 \ell$ water with trihalomethanes content of $40 \mu \mathrm{g} / \ell$ is boiled to completely vaporize the trihalomethanes in a space of $10 \mathrm{~m}^{3}$, the concentration of trihalomethanes in the air is calculated to be $12 \mu \mathrm{g} / \mathrm{m}^{3}$.

This concentration will become higher if trihalomethanes are newly generated during the heating. If an activated carbon column is placed at the outlet of the circulation pipe as shown in Fig. 1, the amount of volatized trihalomethanes will be smaller compared with that in the case of boiling without activated carbon column.

The European Office of WHO proposed $30 \mu \mathrm{g} / \mathrm{m}^{3}$ as target value for a total concentration of organic halogenated compounds in room air ${ }^{23}$. Although the exposure by inhalation of trihalomethanes volatized in a room due to boiling the water will not be the level which immediately causes a problem, it is desirable to ventilate the room during the boiling of water.

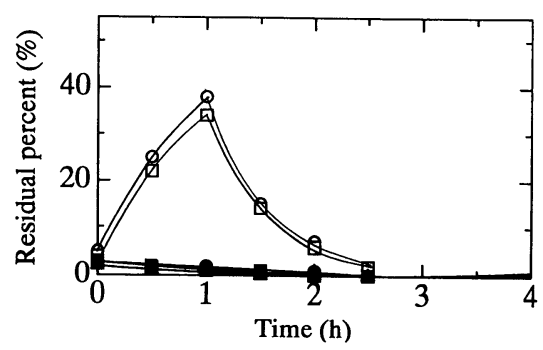

Fig. 10 Variation in the residual percentages of trihalomethanes at $95{ }^{\circ} \mathrm{C}$ with time after 5 min boiling.

Test solution was prepared with tap water. Amounts of activated carbon ( $g$ ) and flow rate ( $/$ min.): $\bigcirc,(0 \mathrm{~g}, 0.0 \mathrm{l} / \mathrm{min}.) ; \square,(0 \mathrm{~g}, 2.5 \mathrm{l} / \mathrm{min}$.); - $(7 \mathrm{~g}, 1.2 \mathrm{l} / \mathrm{min}$ ); $\mathbf{\square},(7 \mathrm{~g}, 2.5 \mathrm{l} / \mathrm{min}.) ; \boldsymbol{\Delta}$, (25 g, 2.5 l/min.) 


\section{REFERENCES}

1) Nabeta, Y. and Nishikawa, M.: A causing substance of chlorious odor and its reduction. J. Jpn. Water Work Assoc., 66, 16-23 (1997)

2) Rook, J.J.: Formation of haloform during chlorination of natural water. Water Treat. Exam., 23, 234 (1974)

3) Hariss, R.H., Brecher, E.M. and the Editors of Consumer Reports: Is the water safe to drink?. Consumer Rep., 39, 436 (1974)

4) U.S. National Institute of Health: Drinking water disinfectants. Environ. Health Perspec., 46 (1982)

5) Symons, J.M., Stevens, A.A., Clark, R.M., Geldreich, E.E., Love, O.T., Jr., DeMarco, J.: Treatment techniques for controlling trihalomethanes in drinking water, U.S. EPA (1981)

6) Tanbo, N.: Tap water and trihalomethane, Gijutsudo Shuppan, Tokyo (1983)

7) Ministerial ordinance regarding water quality standard, Ordi. No.69 M.H.W.

8) Yagi, S: Method of expression of odor in tap water and method of measurement of strength of mold odor and detected concentration. J. Odor Res. Eng., 20, 309-319 (1989)

9) Matsushita, J. and Yoshida, M.: Relationship between attenuation of residual chlorine and rise and fall of trihalomethane in tap water by boiling. Bull. Publ. Health Inst. Hyogo Pref., 19, 116-117 (1984)

10) Hasegawa, K, Utsunomiya, A. and Setsuda, S.: Concentration and change of volatile organic compounds in drinking water by boiling procedure. Bull. Kanagawa P.H. Lab., 26, 43-47 (1996)

11) Tamagawa, K., Inoue, Y., Sugano, T., Seki, T. and Kondo, S.: Studies on trihalomethanes (Third reports). Rep. Sendai Munici. Inst. Publ. Health., 11, 233-236 (1981)

12) Kousaka, Y., Ueda, T. and Hashimoto, M.: Studies regarding halogenated organic compounds contained in tap water (III). Jpn. J. Hyg., 37, 158 (1982)

13) Yamazaki, S., Kurohane, T., Sasaki, F., Aizawa, T. and Magara, Y.: Changes in concentrations of low- boiling point organic halogenated compounds in drinking water with boiling by purge-trap method. Ann. Rep. Suginami City Inst. Publ. Health., 10, 6671 (1992)

14) Sugaya, N., Nakagawa, T., Yamamoto, C., Takahashi, Y. and Morita, M.: Change of disinfection byproducts concentration in water during heating. $J$. Environ. Chem., 7, 801-808 (1997)

15) Nakanishi, S. and Hino, T.: Boiling technique for removing volatile organic compounds from drinking water. Bull. Publ. Health Inst. Chiba Pref., 18, 2528 (1994)

16) Takahashi, Y., Onodera, S. and Morita, M.: Characterization and determination of halogenated organic compounds in river water and drinking water. $J$. Environ. Chem., 10, 273-280 (2000)

17) Takahashi, Y. and Morita, M.: Change of concentration and compositions of halogenated disinfection by-products in tap water during heating. J. Environ. Chem., 8, 465-472 (1998)

18) Urata, T., Tokumitsu, S., Kiyono, R. and Tasaka, M.: Change in concentration of residual chlorine, trihalomethane and 2-methylisoborneol in aqueous solutions under various heating conditions. J. Environ. Chem., 9, 29-37 (1999)

19) Hassler, J.W.: Activated carbon, Chem. Publ. Co., New York (1963)

20) Investigation on chemical substance catalog preparation 3. Literature survey of exposure assessment of chloroform, Environ. Agen. (1996)

21) Yoshida, T., Andoh, K. and Fukuhara, M.: Exposure to volatile organic chlorine chemicals and estimation of adsorption of them in residence. J. Jpn. Atmos. Environ., 33, 371-383 (1998)

22) Iwata, T., Takahashi, M. and Kimura, K.: Field measurement and risk assessment on the organohalogen compounds include in indoor air. Tech. Rep. Ann. Meet. Soc. Heating, Air-Conditioning Sanitary Eng. Jpn., 25-28 (1999)

23) WHO, Indoor air quality: Organic pollution, EURO Rep. Stud. 111, 1987 